\title{
OS CAMINHOS DO DIREITO: OBSTÁCULOS, FERRAMENTAS E PROCEDIMENTOS IMPORTANTES PARA SE GARANTIR A EFETIVIDADE DA LEI
}

\section{THE WAYS OF THE LAW: OBSTACLES, IMPORTANT TOOLS AND PROCEDURES TO ENSURE THE EFFECTIVENESS OF THE LAW}

\author{
DÉBora Suelen Gomes de SOUZA \\ Bacharel em Comunicação Social com habilitação em jornalismo e \\ estudante de Direito do Centro Universitário Jorge Amado. \\ deborasuellen@hotmail.com \\ RebecCa TeiXeira NeVes \\ Estudante de Direito do Centro Universitário Jorge Amado.
}

\begin{abstract}
RESUMO
Este artigo de revisão discute o papel do Tribunal de Justiça na Bahia a fim de promover um direito constitucionalmente previsto e teoricamente garantido, o acesso à justiça. A princípio, a abordagem se faz por meio da teoria sociológica sobre o campo jurídico. Tomamos o texto literário Diante da Lei, de Franz Kafka, como fundamento para discutir a teoria de Pierre Bordieu sobre o poder simbólico e os tipos de capitais presentes no campo jurídico. A revisão bibliográfica sobre o acesso a justiça reflete sobre as exigências e as restrições que a população, especificamente a mais pobre, enfrenta para buscar a efetividade do direito. Apesar de o acesso ser, teoricamente, direito de todos, de forma a obedecer à isonomia Constitucional, o que acontece é uma seletividade decorrente daquilo que se exige de forma direta ou indireta para adentrar ao campo jurídico. Ou seja, os critérios formais e os laços estreitos da justiça com as classes mais favorecidas implica numa refinagem a respeito de quem tem poder ou não para acessar este campo. Destacam-se as peculiaridades das normas constitucionais que deveriam ser direcionadas à sociedade como um todo, através de análise das funções dos magistrados que possuem a responsabilidade para exercer, efetivar e promover essas normas, além de analisarmos criticamente a respeito das instituições que auxiliam na efetivação desses direitos. Aborda-se assim, as condições que não condizem com os parâmetros constitucionais estabelecidos pelo Estado Democrático de Direito e pelo principio da isonomia que estabelece igualdade de direito para todos os indivíduos.
\end{abstract}

Palavras-chave: poder simbólico; acesso a justiça; campo jurídico; democracia

\begin{abstract}
This review article discusses the role of the Court in Bahia to promote a right constitutionally theoretically predicted and guaranteed access to justice. In principle, the approach is done through the sociological theory about the legal field. We take the literary text Before the Law by Franz Kafka, as a basis for discussing the theory of Pierre Bourdieu on symbolic power and the types of capital present in the legal field. A literature review on access to justice reflects on the demands and restrictions that the population, especially the poorest, face to seek the effectiveness of law. Although access is theoretically right for everyone, so obey the Constitutional equality, what happens is a result of what selectivity is required directly or indirectly to enter the legal field. That is, the formal criteria and the close ties of justice with the higher classes implies a refinagem about who has power or not to access this field. We highlight the peculiarities of constitutional norms which should be directed to society as a whole, through analysis of the roles of magistrates who have the responsibility to exercise, carry out and promote these standards, and analyze critically about institutions that assist in effecting these rights. Covers up well, conditions that do not match the parameters established by constitutional democratic rule of law and the principle of equality establishing equal rights for all people.
\end{abstract}

Keywords: symbolic power, access to justice, legal field; democracy 


\section{SUMÁRIO}

INTRODUÇAO; 1 DIANTE DA LEI E OS OBSTÁCULOS DA JUSTIÇA; 2 AS FUNÇÕES DOS MAGISTRADOS; 30 PAPEL DO TRIBUNAL DE JUSTIÇA DA BAHIA; 4 A DEMOCRACIA E O ACESSO À JUSTIÇA;CONCLUSÃO; REFERÊNCIAS.

\section{INTRODUÇÃO}

O direito é um campo em que se travam lutas e batalhas em favor da garantia normativa que é assegurada ao indivíduo contra as injustiças. Para se alcançar as recompensas deve-se transpor os obstáculos, revestir-se de capitais e ter coragem para enfrentar todas as instâncias e tribunais. $\mathrm{O}$ guerreiro precisa estar revestido de armadura e de armas. A luta requer atributos como resistência, coragem, sabedoria, estratégias para saber o momento exato de agir e utilizar cada mecanismo, seja de defesa ou ataque. "A luta não é, pois um elemento estranho ao direito, mas sim uma parte integrante de sua natureza e uma condição de sua idéia”. (IHERING, 2010 p.22)

Mas quais são os obstáculos existentes e que armas possibilitam essa luta pelo Direito? De que forma os capitais tornam-se aliados? Qual é o papel social dos magistrados e do poder público contemporâneos na acessibilidade desses campos? Este artigo visa abordar as variáveis que impedem a eficácia e o acesso ao campo jurídico, levando em consideração as relações entre o poder simbólico apresentado por Bourdieu e os capitais simbólico, social, econômico e cultural que podem contribuir para a luta contra a injustiça e a impunidade. Há também uma reflexão a cerca das funções dos juristas e do poder público, agente capaz e competente para facilitar ou dificultar o acesso às instâncias.

Outro ponto relevante é a discussão a cerca do acesso à justiça dentro da esfera de Estado Democrático de Direito, o qual estabelece a soberania popular como um dos poderes supremos. Com isso, não se pode restringir ao povo, detentor desse poder, a acessibilidade ao Direito.

É importante ressaltar que o ponto de partida para esse artigo é a parábola Diante da Lei de Franz Kafka, na qual lida com as dificuldades para incluir o homem comum no complexo campo jurídico, dotados de regras específicas e que demandam competência para a obtenção do Direito de se dizer o Direito. 


\section{DIANTE DA LEI E OS OBSTÁCULOS DA JUSTIÇA}

A parábola Diante da Lei de Franz Kafka mostra os obstáculos existentes que os cidadãos comuns enfrentam para poder ter acesso ao Poder Judiciário. Compreendemos que, embora tenha seus direitos assegurados em lei, o homem do campo tem dificuldade para garanti-los de forma eficaz.

Silva (2009) utiliza-se da crítica de José Renato Nalini para conceituar a falta de acesso a justiça:

Em lugar da orgulhosa proclamação da vítima: 'Vou procurar por meus direitos', o que se vê aqui é a ironia do infrator: 'Vá procurar a Justiça'. Sabem todos como funciona a Justiça: a proliferação de decisões ilegais e de arbitrariedades significa que a administração e outros centros de poder (inclusive os privados) se sentem relativamente impunes em face de suas irregularidades. (NALINI 2002 apud SILVA, 2009)

Algumas dificuldades como a falta de conhecimento, um intermediador entre o cidadão comum e a justiça (no caso o advogado para assessorar quais procedimentos, formas e o que deve ser feito), questões econômicas (custeios das despesas necessárias), as limitações em que restringem as linguagens jurídicas, as questões sociais, lentidão nos processos e outras, atrapalham a luta das pessoas pelos seus direitos. Com isso, percebe-se que o direito na sua aplicabilidade é um privilégio de poucos.

O Judiciário se vê acusado de atender a uma faixa cada vez mais estreita da comunidade. Os despossuídos encontram suas portas cerradas. Os poderosos não serem curvam à lentidão dos processos convencionais. 0 povo desacredita de sua justiça. (NALINI, 1997)

Na parábola, o cidadão que está diante da lei tenta ter acesso, mas é impedido por um porteiro que o alerta sobre os empecilhos. A entrada não é admitida de imediato, mas, posteriormente, o cidadão poderia adentrar a este campo desde que tivesse as ferramentas adequadas para enfrentar os outros porteiros, mais poderosos do que aquele que estava diante da lei. No final, quando já está quase morrendo, o cidadão descobre que o acesso era restrito e reservado somente a ele, mas em virtude da falta de conhecimento, ele não pode gozar dos próprios direitos.

Essa parábola nos convida à reflexão sobre o acesso aos tribunais judiciários. 0 art. $5^{\circ} \mathrm{da}$ Constituição Federal estabelece, entre as garantias fundamentais, o princípio da garantia da via judiciária e do acesso à justiça, em que não poderá o Poder Judiciário ser um obstáculo para 
efetivação do Direito. “A lei não excluirá da apreciação do Poder Judiciário lesão ou ameaça a direito". (BRASIL, 1988 art. 5 CF, XXXV)

No senso comum, a idéia de Poder Judiciário está associada a um sistema lento, burocrático, deficiente e que está a serviço de uma parcela da população que detém o poder.

Em verdade, se o próprio Estado naufraga em tormentosa crise, o Judiciário não passa intangível de críticas pela sociedade. A descrença do destinatário, o preconceito natural por se tratar de prestação governamental, a certeza da lentidão do serviço, ademais complicado e dispendioso, a distância imensa entre as necessidades e as urgências da comunidade e o ritmo da resposta jurisdicional possível são constatações a que os atentos já chegaram.(SILVA, 2009)

Se algum indivíduo se sentir injustiçado de alguma forma, pode acionar a justiça. Esse direito é garantido na Constituição Federal brasileira (1988) a todos os cidadãos, através do principio da isonomia que determina o caput do art. $5^{\circ}$ da Constituição Federal assegurando que não pode haver distinções.

Todos são iguais perante a lei, sem distinção de qualquer natureza, garantindo-se aos brasileiros e aos estrangeiros residentes no País a inviolabilidade do direito à vida, à liberdade, à igualdade, à segurança e à propriedade. (BRASIL, 1988 caput art. $\left.5^{\circ}\right)$

Entretanto, por conseqüência das desigualdades, uma parcela da população é desprovida até mesmo do que a Constituição estabelece como Direito Fundamental.

Mas é verdadeiramente trágica se considerada a dimensão do acesso do pobre aos direitos. Os despossuídos são privados até dos direitos fundamentais de primeira geração, para eles meras declarações retóricas, sem repercussão em sua vida prática. (NALINI, 1997)

Essa luta pelo direito é algo que exige, antes de qualquer outra coisa, conhecimento daquilo que se tem direito. As relações jurídicas envolvem uma disputa pelo poder, em que o capital cultural destaca-se como um elemento importante. O capital cultural é um "conceito que explicita um tipo de capital, um novo recurso social, fonte de distinção e poder em sociedades em que a posse deste recurso é privilégio de poucos” (Bourdieu,1996, p. 32).

Capital, segundo a teoria de Pierre Bourdieu, significa acúmulos, não apenas de materiais econômicos, mas todo e qualquer recurso que exerça influência sobre atividades que envolvam a sociedade. Em sendo assim, o capital cultural é aquele que decorre de saberes e conhecimentos, atrelando-se ao poder simbólico, que deriva dos instrumentos de comunicação, influência e conhecimento. Ou seja, as condições sociais e culturais que o sujeito tem perante a sociedade para gozar daquilo que é assegurado na codificação máxima. O leigo que não domina a técnica 
mesmo lançado no campo estará excluído, pois não terá conhecimento suficiente para adentrar as portas.

No caso jurídico, especificamente, a interpretação da lei (capital cultural) é fundamental para que se tenha domínio do que se tem direito e quais são os limites existentes. O Nalini (1997) atribui ao juiz a essa responsabilidade de disseminar a informação a cerca do direito.

Os juízes e as instituições do Judiciário devem ter o compromisso de divulgar o Direito. Em uma sociedade pobre como a brasileira, o juiz deve também repensar o dogma da imparcialidade, de maneira a contribuir para a redução das desigualdades sociais. (NALINI, 1997)

Além do cultural, os capitais sociais, econômicos e simbólicos também possuem sua relevância dentro do campo jurídico. O capital econômico tange as condições financeiras necessárias para realização e manutenção dos processos jurídicos que, em virtude de sua morosidade, torna as custas maiores, inviabilizando o acesso para as classes menos favorecidas. O capital econômico o qual me refiro não é para utilizar de meios ilegais para "comprar" ou conseguir benefícios, mas para custear as despesas necessárias que envolvem um processo, como a contratação de um advogado.

O capital econômico é aquele voltado para rendas, ou seja, o homem comum detentor de capital econômico terá vantagens em cima daquele que este não possui. Uma vez que o portador deste capital tem meios mais vantajosos para acessar a justiça através dos profissionais que possuem capital simbólico, aquele decorrente de uma boa relação em sociedade, dotados de mérito, torando-se assim conhecido e competente no campo. A contratação de um profissional que é detentor de capital simbólico torna mais viável o acesso à justiça. Em outras, o capital simbólico é o que será usado como mediação entre o homem comum e o profissional jurista.

A defensoria pública é uma alternativa para a população que não tem condições de custear os honorários advocatícios, entretanto, a sobrecarga de trabalho e as condições de trabalho da defensoria dificulta na agilidade do processo. A defensoria pública é uma forma de consulta jurídica que foi criada para atender a população menos favorecida e possui diversas deficiências em seu funcionamento, o que dificulta e inviabiliza a eficácia do trabalho destas instituições. Um exemplo que podemos citar é a Defensoria Pública da União que é pequena e possui um número de membros inferior a Defensoria Pública dos Estados.

No entanto, as defensorias públicas dos Estados também são pequenas para atender a necessidade de uma sociedade cheia de conflitos. Em virtude dessas deficiências, a assistência jurídica se torna seletiva. E dessa forma, o Estado deve estimular as iniciativas que surgem da 
OS CAMINHOS DO DIREITO: OBSTÁCULOS, FERRAMENTAS E PROCEDIMENTOS IMPORTANTES PARA SE GARANTIR A EFETIVIDADE DA LEI

DÉBORA SUELEN GOMES DE SOUZA REBECCA TEIXEIRA NEVES

sociedade brasileira para auxiliar na resolução de conflitos e prestar serviço à população de forma mais eficaz. É o caso da Capacitação jurídica de líderes comunitários. "Refere-se a programas governamentais e não governamentais voltados para a preparação de integrantes da comunidade como mediadores na solução de conflitos locais." (SANTOS, 2007 p. 52)

A capacitação de membros das comunidades mais pobres pelos Tribunais de Justiça Estaduais, poderá amparar e passar orientação jurídica àqueles que não se adéquam às exigências formais do âmbito jurídico.

No âmbito das iniciativas não-governamentais de resolução de conflitos dirigidas para a capacitação de líderes comunitários e criação de escritórios populares de mediação, cito a organização não governamental Jus Populi, na Bahia. (SANTOS, 2007 p. 52)

O capital social ${ }^{2}$ que é a relação social dos que buscam e daqueles que tem o direito de dizer o direito dentro da esfera jurídica, que, na maioria dos casos atua como fator determinante na resolução de lides, pois a influência dos agentes, dotados de capital cultural e simbólico determina o resultado dos litígios em favor da parte detentora desses capitais.

O capital social é o "conjunto de recursos atuais ou potenciais que estão ligados à posse de uma rede durável de relações mais ou menos institucionalizadas de interconhecimento e de inter-reconhecimento ou, em outros termos, à vinculação a um grupo” (BOURDIEU,1998, p. 67). A influência que possui um advogado ou os conhecimentos que ele possui, pode auxiliar no andamento do processo. O capital social do homem que busca seus direitos também é importante, pois através dele pode-se adentrar em portas de difícil acesso para o homem comum. De fato essa questão é bastante controvérsia, entretanto, somos componentes de uma sociedade em que o status social é uma ferramenta que facilita e agiliza o resultado das coisas.

[...]0 capital simbólico, diferentemente das outras modalidades de capital, não é imediatamente perceptível como tal e os efeitos de sua duração também obedecem a lógica(s) diferente(s) [...] é, a grosso modo uma medida do prestígio e/ou do carisma que um indivíduo ou instituição possui em determinado campo[...][...]Como ele é um tipo de capital cuja posse permite um (re)conhecimento imediato da dominação do elemento que o possui sobre os demais elementos do campo, o capital simbólico é assim o instrumento principal da violência simbólico, ao impor seu peso sobre os que não o possuem ou o possuem em quantidades inferiores em um dado campo. (SANTOS, 2007)

Esse capital recai sobre a sociedade de forma invisível, pois é aquele que decorre do mérito, ou seja, aqueles que possuem maior prestígio e destaque dentro do campo em que atuam são portadores de capital simbólico. Os detentores desse capital possuem maior possibilidade de obter um resultado positivo nas lides pois, o seu reconhecimento como profissional o destaca, fazendo com que os outros agentes do campo o vejam como experiente 
OS CAMINHOS DO DIREITO: OBSTÁCULOS, FERRAMENTAS E PROCEDIMENTOS IMPORTANTES PARA SE GARANTIR A EFETIVIDADE DA LEI

DÉBORA SUELEN GOMES DE SOUZA RebeCCA TEIXEIRA Neves

na área, causando impressão positiva e beneficiando os que buscam seus serviços, é o caso dos advogados dotados de reconhecimento profissional.

O capital simbólico não está apenas atrelado aos profissionais da área jurídica, mas também àqueles que buscam um agente da área para efetivar o seu direito. Quando um homem comum, que não atua dentro do campo jurídico, mas é dotado de capital simbólico adquirido por herança ou por status social, uma vez que ele está inserido na classe social mais favorecida, na qual, consequentemente, os profissionais juristas merituosos fazem parte, a tendência de o processo favorecer a estes é provável. Pois o capital simbólico se adquire também através da convivência, dos meios frequentados, do parentesco e da relação amistosa entre os sujeitos que convivem em uma esfera social compatível.

Podemos também perceber que as relações jurídicas denotam de uma relação de poder. O poder simbólico é o resultado da comunicação e do conhecimento que adquirimos através da nossa compreensão do mundo. Ele pode variar conforme a classe social, a qual permite maior acesso ou restrição, conforme o status que possui o indivíduo.

As diferentes classes e frações de classes estão envolvidas numa luta propriamente simbólica para imporem a definição do mundo social mais conforme aos seus interesses e imporem o campo das tomadas de posições ideológicas reproduzindo em forma transfigurada o campo das posições sociais. (BORDIEU, 1998 apud RODRIGUES el al. 2010 p.4946)

Este poder atua de maneira imperativa e impositiva, interferindo na maneira como o mundo passa a ser visto, podendo ser responsável pelas distorções do mundo contribuindo para as desigualdades existentes em virtude de ocasionar um sistema de dominação de uma classe sobre a outra.

Rodrigues (et al 2010, p. 4946), cita como exemplo o fato que os menos favorecidos possuem os mesmos direitos que o rico, dentro dos preceitos constitucionais, entretanto, eles acabam tendo menos acesso aos direitos por não possuírem ferramentas suficientes para adentrar ao campo jurídico, o qual é estruturado. "O direito, por exemplo, é estruturado: há instituições como escolas, tribunais, secretarias, arquivos, etc., além das estruturas simbólicas: linguagem específica, roupas, etc. Mas é também estruturante, isto é, vai expandindo a sua própria estrutura".

O campo jurídico é conceituado por Bourdieu (apud RODRIGUES et al, 2010, p. 4947) como espaço em que os legitimados disputam sobre o direito de dizer o direito.

[...] lugar da concorrência pelo monopólio do direito de dizer o direito, quer dizer, a boa distribuição (nomos) ou a boa ordem, na qual se defrontam agentes 
investidos de competência ao mesmo tempo social e técnica que consiste essencialmente na capacidade reconhecida de interpretar (de maneira mais ou menos livre ou autorizada) um corpus de textos que consagram a visão legítima, justa, do mundo social. É com esta condição que se podem dar as razões quer da autonomia relativa do direito, quer do efeito propriamente simbólico de desconhecimento, que resulta da ilusão da sua autonomia absoluta em relação às pressões externas.

O direito possui linguagem específica, no qual exige capital cultural e simbólico, pois o campo jurídico requer técnicas que interferem no resultado justo. 0 "direito de se dizer o direito" é o que condiciona essas relações de dominação e poder.

É no campo jurídico que se debatem os profissionais investidos de competência social e técnica para tanto, em busca "do monopólio do direito de dizer o direito". A competência técnica para ingresso no campo jurídico implica a capacidade reconhecida de interpretar os textos jurídicos que consagram a visão "justa" do mundo social. É do fato de ser somente nesse campo jurídico que se admite o embate destes técnicos, interpretando textos pré-existentes e, através dessa disputa, fazendo com que a jurisdição se distancie cada vez mais da concepção comum de equidade, que resulta a ilusão da sua autonomia absoluta em relação às pressões externas. (RODRIGUES et al 2010, p. 4948)

A aquisição dos direitos é autorizada pelos legitimados de dizer do direito, são conferidos a eles o poder de resolver conflitos através da interpretação da lei. Isso constitui uma relação que envolve o poder simbólico, visto que os debates ocorrem em instâncias hierarquizadas.

Os dominados se sentem incluídos, ao verem suas conquistas elevadas ao status de corpus jurídico, mas não percebem que suas conquistas são apenas aquelas autorizadas pelos detentores do saber jurídico. Assim, o reconhecimento dessas conquistas também não passa de um método que contribui para a eficácia simbólica do direito, uma vez que torna mais imperceptível a questão da dominação. (RODRIGUES et al, 2010 p. 4948)

Além do conhecimento sobre os campos e aquisição dos capitais, é necessário que se viabilize a agilidade do processo. A prática judiciária precisa ser ágil para que o gozo dos direitos estabelecidos pelo Estado-juiz sejam feitos ainda em vida. Quantos homens do campo como o da parábola diante da lei morrem sem gozar dos seus direitos? A morosidade dos procedimentos e a demora dos julgamentos contribuem para a efetividade do direito. 0 art. 37 , § $6^{\circ}$, da CF determina que é competência do Judiciário buscar eficiência nos seus serviços.

O serviço judiciário consiste, incontestavelmente, em um serviço público, imposto aos cidadãos pelo Estado, que deve zelar por um certo grau de perfeição 
OS CAMINHOS DO DIREITO: OBSTÁCULOS, FERRAMENTAS E PROCEDIMENTOS IMPORTANTES PARA SE GARANTIR A EFETIVIDADE DA LEI

DÉBORA SUELEN GOMES DE SOUZA RebecCA TEIXEIRA NEVES

tanto na sua organização quanto no seu funcionamento, bem como responder pelos danos acaso daí provenientes. (BRASIL, 1988 art. $37, \S 6^{\circ}$ )

Entre tantas questões existenciais, não podemos deixar de citar a corrupção existente dentro do poder judiciário em que há casos de vendas de sentenças por parte dos magistrados. 0 caso mais polêmico e conhecido foi do casal de juízes condenados por essa prática. Em 2003, os 18 desembargadores que integravam a Corte Especial do Tribunal Regional Federal (TRF-1) decidiram pela condenação do desembargador federal Eustáquio da Silveira e sua mulher, a juíza federal Vera Carla da Cruz Silveira.

\section{AS FUNÇÕES DOS MAGISTRADOS}

Desde o principio da história, a figura do juiz já representava um aspecto importante no poder de decisões sobre os problemas existentes na sociedade. Quando não existia a figura do juiz, os reis eram quem solucionava os tumultos. A Bíblia, por exemplo, narra a história de duas mulheres que diziam ser mãe de um bebê e para resolver esse impasse foram procurar o rei Salomão.

Essas duas mulheres tiveram os filhos juntas, mas um deles morreu, então ambas disputavam a guarda da criança que sobreviveu. Sendo assim, ambas foram até o rei Salomão, buscando que este decidisse sobre quem ficaria com a criança. 0 rei sugeriu que cortassem o bebê ao meio e a cada uma delas fosse dado um pedaço. Uma das mulheres se desesperou e disse que preferia ver o filho vivo nos braços da outra, do que ver o filho morto. Ao perceber o desespero e o sentimento desta mulher, Salomão percebeu que se tratava da verdadeira mãe, a quem o bebê deveria ser entregue. (BIBLIA, 1 Reis 3:16-28)

É indiscutível o poder de decisão que possuem os magistrados na solução de conflitos jurisdicionais. Estes representam o Estado e têm o dever de contribuir para o alcance da justiça em casos concretos, facilitando o andamento processual. O Código de Processo Civil (CPC) atribui funções para todos os envolvidos no processo, em que se busca o julgamento de forma neutra, imparcial e proba.

Art. 14. São deveres das partes e de todos aqueles que de qualquer forma participam do processo: I - expor os fatos em juízo conforme a verdade; II proceder com lealdade e boa-fé; III - não formular pretensões, nem alegar defesa, cientes de que são destituídas de fundamento; IV - não produzir provas, nem praticar atos inúteis ou desnecessários à declaração ou defesa do direito. V cumprir com exatidão os provimentos mandamentais e não criar embaraços à efetivação de provimentos judiciais, de natureza antecipatória ou final. (BRASIL, 1988 art.14 inciso I do Código de Processo Civil) 
Essas normas estão relacionadas ao princípio da Verdade Real, que objetiva a segurança jurídica baseada na veracidade formal dos fatos, para que o magistrado tome a decisão de forma justa e coerente. "Verdade real é o princípio pelo qual o juiz deve investigar e apreciar o conjunto probatório de forma que dele emirja seu convencimento em correspondência ao ocorrido efetivamente". (COSTA, 2005 p.1)

O ativismo judicial deve ser visto como a maneira justa da solução do litígio, buscando adequar as normas ao caso concreto, visando a verdade real e a segurança jurídica.

Por tudo até aqui exposto, ao hercúleo trabalho do juiz de dar a justa solução ao litígio, balizado pela busca da verdade real e pelo princípio da segurança jurídica, faz-se mister acrescentar noções de hermenêutica e de interpretação de normas, pois vezes muitas se relacionam (ao papel do juiz). (COSTA, 2005 p. 7)

A função do juiz no exercício jurisdicional requer responsabilidade e comprometimento, principalmente no que se refere à problemas sociais, constituindo para um mundo mais justo e menos desigual, impedindo as arbitrariedades que atuam contra a sociedade.

Os juízes não têm as chaves para resolver todos os problemas do mundo, mas devem assumir o desafio do momento histórico e produzir algo de mais sólido para maximizar a capacidade de resolução de conflitos, transformação social e pacificação de cizânias. Isto é que representa uma ampliação de alternativas para profilaxia harmônica das diferenças sociais, consectário óbvio para aproximar-se do real alcance do acesso à Justiça.(SILVA, 2009)

O jurista Francisco das C. Lima Filho (2002), no artigo Acesso à Justiça e o Juiz moderno, atribui responsabilidades e características que devem ser inseridas no exercício das funções do magistrado, vetando atitudes que não condizem com o papel do juiz e as expectativas da população em relação as suas atribuições.

0 juiz moderno não tem apenas um papel profissional, de intérprete e aplicador da lei, especialmente da lei estatal. Deve, sobretudo, envolver-se, institucional e individualmente, com a tarefa de criação e mediação na comunidade, pois não pode se esquecer que quando decide, está dizendo o direito das pessoas. Esperase do juiz uma atuação, enquanto cidadão, no sentido de ampliar os espaços democráticos, colocando seus conhecimentos a serviço da comunidade, criando, modificando e aperfeiçoando técnicas que possam atender aos anseios e dramas sociais. (LIMA FILHO, 2002 p.1)

Lima Filho (2002) acrescenta ainda que dentre as expectativas da atuação do juiz, está atuação que possa aproximar a ciência e ética, atuando de forma racional e justa. Na aplicabilidade do direito que tem relevância no regimento das relações sociais, busca-se a segurança jurídica, a justiça nas soluções de conflitos e compromisso com a sociedade. 
0 exame dos sentimentos morais predominantes na sociedade e a análise das condições econômicas e sociais reinantes, aliados à vontade das partes, deve representar um modelo de comportamento a ser seguido pelo juiz moderno. Precisa, pois, adotar uma postura crítica como intérprete do direito, de forma a aproximar a lei e o direito, segurança jurídica e justiça, pugnando pela redução das desigualdades sociais, por uma melhor divisão da riqueza, pela harmonização dos interesses privados antagônicos, pelo justo equilíbrio das relações jurídicas e pelo abrandamento do direito individual sobre o direito da coletividade: direito dos grupos sociais, tais como os sindicatos, das associações de moradores, de consumidores, dos sem terra, dos sem teto, etc. (LIMA FILHO, 2002)

Sendo aplicado um direito reto e justo, o direito protege a princípios como a dignidade da pessoa humana, alcançando a finalidade do Estado que é o bem comum. Com isso, o juiz na modernidade deve estar preocupado com as questões de proteção dos direitos dos indivíduos, o respeito ao órgão que está vinculado, mas não dependente, pois a dependência causa o engessamento do direito, e este requer liberdade.

Enfim... falo do juiz que a sociedade espera para o século XXI: imparcial, honesto, digno do cargo que ocupa, conhecedor do direito e não, necessariamente, jurista, arrogante na decisão da causa, porém humilde no trato com os sujeitos que intervém no processo e, principalmente, respeitador do Tribunal à que está vinculado, mas não submisso. A submissão é a vergonha da toga. $O$ respeito, seu engrandecimento. (RANGEL, 2001 p.2)

O juiz deve ter uma postura crítica diante dos fatos, se comportando não simplesmente como um interprete da lei, mas uma figura ativa no processo e que esteja em sintonia com a realidade social da população, principalmente os grupos minoritários e os que têm pouco acesso ao poder judiciário.

Com efeito, um juiz dotado de uma postura apenas dogmática, preso às amarras da lei, de julgar conforme essa mesma lei, sem qualquer percepção de que, a lei seja apenas um referencial, o mais importante, é verdade, mas apenas um referencial, e de que o Judiciário é Poder do Estado e como tal, cabe a ele, tão sério como o do Legislativo, buscar o que é melhor para a sociedade, pode representar uma barreira intransponível para o acesso à justiça. (LIMA FILHO, 2002).

Lima Filho (2002) acrescenta ainda, a exigência de um juiz que observa os dados referentes à cultura, à história e às próprias necessidades sociais do povo, para a justiça possa ser, de fato, acessível a todos, principalmente à população menos favorecida. Mas infelizmente isso não tem acontecido, visto que, o judiciário tem sido acusado de se distanciar dos interesses populares e atender a interesses restritos conforme a maioria das vezes pela conveniência.

O Estado, enquanto pessoa jurídica de direito público, dotado de atributos que lhe permitem operacionalizar os fins para os quais foi criado, deve assegurar a cada indivíduo o máximo possível de liberdades básicas, compatíveis e 
necessárias com um sistema de liberdades para todos, ordenando e eliminando as desigualdades econômicas e sociais, de maneira que sejam para maior benefício dos menos favorecidos. (RANGEL, 2001 p.2)

O papel que os juízes desempenham hoje na sociedade confronta com o papel que é delegado a eles, como agentes do direito, de fazer justiça de forma imparcial, mantendo a igualdade entre os envolvidos. No entanto o que vemos hoje é um reflexo histórico, é um quadro deficiente da prestação jurisdicional, na qual o vínculo entre o judiciário e as classes elitistas se estabelecem de forma natural, muitas vezes encarada e tolerada pela sociedade como uma conduta normal do cotidiano, como era na antiguidade, em que existia uma troca de favores entre as classes mais favorecidas. Desta forma, o papel que os juízes atualmente exercem em sociedade é basicamente o que se via em outras épocas, sentenciando em favor do interesse da classe na qual ele mesmo está inserido, causando assim uma seletividade de quem pode adentrar à justiça e quem não pode.

Outro ponto importante é que as escolhas políticas estão sendo deixadas nas mãos dos juízes, a fim de que estes promovam as normas emanadas pelo Estado. A exemplo, podemos observar os direitos sociais e garantias fundamentais que são normas e devem ser efetivadas pelo Estado. Em sendo assim, o juiz, como detentor do direito de dizer o direito, se torna figura indispensável na prática dessas normas em sociedade, de forma que não o faz, ou faz arbitrariamente, se utilizando desse cargo público para exercer sua função a mercê de seus interesses pessoais. Não se preocupando em refletir a respeito da tamanha responsabilidade que a eles é conferida, pois, por muitas vezes o prejuízo arcado pelos que são desprovidos dos capitais necessários para ingressarem na lei, consequência de uma sentença irresponsável, é duradouro e catastrófico.

Mas, o que se pode fazer para evitar que os juízes se comportem como monopolizadores do direito? Deve-se combater o isolamento da Magistratura, ou seja, os juízes não formam um corpo á parte do sistema estatal, e sim estão inseridos no sistema. Dessa forma, a inclusão de membros que não fazem parte do poder Judiciário na formação de Conselhos de controle das atividades dos juízes e altamente importante. A emenda Constitucional 45 trouxe a fixação da participação do Ministério Público, da Câmara dos Deputados e do Senado Federal para indicação de membros no Conselho Nacional de justiça. 


\section{O PAPEL DO TRIBUNAL DE JUSTIÇA DA BAHIA}

"Os Estados organizarão sua Justiça, observados os princípios estabelecidos nesta Constituição". (BRASIL, art. 125 da CF/88). Cada Estado, como ente federativo, possui a capacidade de auto- organização/normatização, o que permite a autonomia de desenvolver a própria legislação dentro dos princípios Constitucionais da Carta Magna e também julgar os casos de conflitos jurídicos existente, possuindo Tribunal de Justiça próprio.

O Tribunal de Justiça da Bahia "tem jurisdição em todo o Estado e é a instância mais elevada do Judiciário Estadual”, cabe a ele a responsabilidade civil da prestação jurisdicional. (BAHIA, 2009) A jurisdição é uma palavra de origem latina, que significa “dizer o direito”. Esse poder é atribuído ao Estado, na figura do juiz, de aplicar o direito, buscando solucionar os conflitos de forma imparcial.

Denota-se, por ambas as vias, que a jurisdição é, em verdade, uma função
estatal inafastável, apresentando-se como incumbência atribuída ao Poder
Judiciário, ao mesmo passo, ressalta ser a garantia de existência do Estado
Democrático de Direito; permanência e manutenção do ordenamento jurídico, e
mais que tudo, respeitabilidade à Constituição Federal no que concerne à
obediência aos seus princípios, valores e vontades. (CARMO, 2005)

No que diz relação à estrutura organizacional, o Tribunal de Justiça da Bahia é composto, atualmente, por 35 desembargadores que são escolhidos pelos critérios de antiguidade e de merecimento.

A aplicabilidade da justiça no Brasil se deu início com as Capitanias Hereditárias, cujo intuito era instituir os costumes vigentes em Portugal.

Em 1532 foi implantada na Vila de São Vicente, após a primeira eleição em todo o Continente Americano, uma estrutura jurídica formada por Juízes Ordinários e Vereadores, para aplicar a lei. No topo desse sistema, reproduzido em outras capitanias, estava o Ouvidor de Capitania, designado pelo donatário e com autoridade revisora. A ele competia julgar as apelações e avaliar as listas eleitorais de Juízes e Vereadores, das quais podia excluir os nomes que não agradassem ao donatário. (BAHIA,2009)

Com a criação do governo administrativo e a escolha do governador-geral Tomé de Sousa, percebeu-se a necessidade de outros mecanismos para promover a justiça, como a criação da ouvidoria geral, em que desembargadores eram designados a revisar sentenças de juízes. Entretanto, eram muitos os conflitos e a insuficiência da Ouvidoria em solucionar os casos fez com que a população reivindicasse a criação de uma corte coletiva, ou de uma Relação, denominação comum aos tribunais de justiça de segunda instância na época. 
A Bahia possui um papel histórico relevante no contexto da implantação da justiça do país, já que foi sediado no nosso Estado o primeiro Tribunal da Relação do Estado do Brasil. Em 1763, a sede do Governo-Geral é transferida para o Rio de Janeiro, que posteriormente, em 1808, passa abrigar também a casa de suplicação. Em 1824, a Constituição estabelece às províncias, a autonomia de instalar suas próprias Cortes. Em 1934, o Tribunal da Relação passou a chamar-se Corte de Apelação e, em 1937, Tribunal de Apelação. Em 1957, passa a ser Tribunal de Justiça do Estado da Bahia.

Entre os princípios estabelecidos pelo Tribunal de Justiça da Bahia está assegurar o acesso à justiça aos cidadãos, com independência, ética e eficiência, visando a paz social, ou seja, o Poder Judiciário tem que assegurar por meio de uma prestação jurisdicional a responsabilidade de solucionar conflitos, contribuindo para a efetividade da justiça no Estado Democrático de Direito.

A obra literária "O Processo", de Franz Kafta, critica o que acontece opostamente aos objetivos do campo jurídico, em que o poder judiciário, que deveria atuar como agente facilitador, acaba impedindo o acesso aos órgãos jurisdicionais. O Tribunal de Justiça da Bahia, no âmbito estadual, é a instância que possui competência do monopólio de dizer o direito.

o campo jurídico é um lugar de concorrência pelo monopólio do direito de dizer o direito... onde agentes investidos de competência ao mesmo tempo social e técnica que consiste essencialmente na capacidade reconhecida de interpretar (de maneira mais ou menos livre e autorizada) um curpus de textos que consagram a visão legítima, justa do mundo social. (Bourdieu, 2006).

Neste campo há critérios muito mais determinantes do que a própria norma. Dentro do mundo jurídico, a norma se molda a quem a interpreta, prevalecendo o caráter de quem a diz. No campo judicial, onde é operado o conflito entre partes, a intervenção simbólica, econômica, social e cultural é o que pesa na resolução das lides, baseada no interesse do hermeneuta. No entanto este campo que objetiva pôr em prática as normas codificadas de forma geral, o faz, na maioria das vezes, de maneira ineficaz, atendendo a interesses individuais e não contribuindo para a justa solução do conflito.

Como direito fundamental, a jurisdição garante ao cidadão o direito de exigência a sua prestação do Estado e mesmo que seja uma prestação muitas vezes infundada, cabe ao Estado julgar. "O direito à tutela jurisdicional ou direito de ação é, como indica o nome, um direito de prestação, porque consiste em obter do Estado essa especial prestação que é a proteção dos direitos violados ou ameaçados de violação". (ROCHA, apud DINIZ, 2004) 
OS CAMINHOS DO DIREITO: OBSTÁCULOS, FERRAMENTAS E PROCEDIMENTOS IMPORTANTES PARA SE GARANTIR A EFETIVIDADE DA LEI

DÉBORA SUELEN GOMES DE SOUZA REBECCA TEIXEIRA NEVES

De acordo com Carmen Lúcia Antunes (2003 apud DINIZ, 2004), “o direito à jurisdição apresenta-se em três fases que se encadeiam e se completam, a saber: a) o acesso ao poder estatal prestador da jurisdição; b) a eficiência e prontidão da resposta estatal à demanda de jurisdição; e c) a eficácia da decisão jurisdita".

Caso algumas dessas fases sejam transgredidas, ocorre a ineficiência do poder judiciário, um dos maiores problemas enfrentados pelo cidadão para a aquisição do direito.

Certamente, nossas leis processuais não são perfeitas, mas, em primeiro lugar, são bastante menos más do que se diz; em segundo lugar, se bem que fossem muito melhores, as coisas não andariam melhor, pois o defeito está, muito mais do que nas leis, nos homens e nas coisas. (CARNELUTTI apud TOMÉ, 2006)

Danielle Alheiros Diniz (2004) faz uma crítica a atual conjuntura do sistema jurídico brasileiro, o qual eterniza os processos. "Seja através de procedimentos lentos, de meios processuais ineficazes ou do difícil acesso dos jurisdicionados às vias processuais adequadas, o Estado parece ter interesse em que aquele processo perdure." (DINIZ, 2004 p.2)

A morosidade no julgamento do processo aliada as burocracias e procedimentos ineficientes são vistos como grandes obstáculos enfrentados pelo cidadão, que muitas vezes abre mão do direito de pretensão por descrédito em relação a atividade jurisdicional do Poder Judiciário. O mal funcionamento do sistema judiciário e a falta de efetividade na prestação jurisdicional representa um desestímulo à luta pelo Direito. Por isso, espera-se que o Estado atue de maneira eficiente, corrigindo erros e sendo responsabilizado quando não exercer de maneira correta o seu papel.

Como serviço público, a prestação jurisdicional deve ser prestada de forma correta e tempestiva. Os erros cometidos por ato jurisdicional devem ser reparados, através da responsabilização do Estado por ser este o órgão que deve prestar o direito constitucional à jurisdição. Desse modo, também deve o poder público ser encarregado de responder pela morosidade na prestação jurisdicional como denegação da justiça. (DINIZ, 2004 p.2)

Outro fator que restringe o acesso à justiça brasileira é a falta de conhecimento que o cidadão tem a cerca do que é direito e da maneira em que se deve fazer valer esse direito existente. Carmem Lúcia Antunes (apud DINIZ, 2004) sintetiza que a falta de conhecimento pode inibir a aplicabilidade do Direito. "Direito positivo não sabido é direito inexistente. Quem dele não sabe, não o reivindica; sem o seu conhecimento, não há o seu exercício".

As normas devem ser ajustadas ao caso concreto, porém para isso, deve-se ter conhecimento da maneira que se deve aplicar. Diniz (2004 p.3) ainda acrescenta que cabe ao Estado a responsabilidade de difundir as informações a cerca da lei. "O direito à jurisdição deve ser dado pelo Estado através de normas expressas que precisam ser levadas ao conhecimento do 
OS CAMINHOS DO DIREITO: OBSTÁCULOS, FERRAMENTAS E PROCEDIMENTOS IMPORTANTES PARA SE GARANTIR A EFETIVIDADE DA LEI

DÉBORA SUELEN GOMES DE SOUZA REBECCA TEIXEIRA NEVES

povo. Ao Estado cabe combater a omissão das suas regras e o difícil acesso às leis e a sua aplicação." (DINIZ, 2004 p.3)

Para melhorar a eficiência no atendimento ao cidadão, o Tribunal de Justiça da Bahia elabora e disponibiliza um Plano Estratégico no qual estipula objetivos. Entre as metas estão a garantia da agilidade nos trâmites judiciais e administrativos, a fim de assegurar a razoável duração do processo; a facilitação do acesso à Justiça, promovendo o acesso ao Poder Judiciário, com o objetivo de democratizar a relação da população com os órgãos judiciais e garantir equidade no atendimento à sociedade; e a promoção da efetividade no cumprimento das decisões judiciais, assegurando o cumprimento das decisões emanadas do Poder Judiciário, a fim de garantir que os direitos reconhecidos alcancem resultados concretos.

Embora estes sejam os objetivos, na maioria das vezes eles não têm eficácia na prática. O que nos deparamos é com uma justiça lenta e as vezes ineficiente e ineficaz, o que nos leva ao descrédito e a desmotivação para a luta pelos nossos direitos.

\section{A DEMOCRACIA E O ACESSO À JUSTIÇA}

O artigo $1^{\circ}$ da Constituição Federal de 1988 estabeleceu que a República Federativa do Brasil, constitui-se em Estado Democrático de Direito. Levando em consideração a interpretação, percebemos que a Constituição frisou instituir um Estado que assegura o exercício dos direitos e os valores supremos relacionados à liberdade, segurança, bem estar, o desenvolvimento, a justiça e igualdade.

O Estado Democrático de Direito Social é definido por Martinez (2003 p.1) como um conceito amplo que abrange a participação popular, a cidadania e a garantia dos direitos individuais.

(...) a organização do complexo do poder em torno das instituições públicas, administrativas (burocracia) e políticas (tendo por a priori o Poder Constituinte), no exercício legal e legítimo do monopólio do uso da força física (violência), a fim de que o povo (conjunto dos cidadãos ativos), sob a égide da cidadania democrática, do princípio da supremacia constitucional e na vigência plena das garantias, das liberdades e dos direitos individuais e sociais, estabeleça o bem comum, o ethos público, em determinado território, e de acordo com os preceitos da justiça social (a igualdade real), da soberania popular e consoante com a integralidade do conjunto orgânico dos direitos humanos, no tocante ao reconhecimento, defesa e promoção destes mesmos valores humanos. De forma resumida, pode-se dizer que são elementos que denotam uma participação soberana em busca da verdade política. (MARTINEZ, 2003 p.1) 
OS CAMINHOS DO DIREITO: OBSTÁCULOS, FERRAMENTAS E PROCEDIMENTOS IMPORTANTES PARA SE GARANTIR A EFETIVIDADE DA LEI

DÉBORA SUELEN GOMES DE SOUZA REBECCA TEIXEIRA NEVES

O conceito de democracia está associado a governo do povo, para o povo (BONAVIDES, p.344) em que a soberania consiste na ideia de Montesquieu, em algo que pertence ao povo. (BONAVIDES, 2000 p.251) Este povo não tem caráter restritivo, ele abrange todas as classes sociais, independente de condição, cor e fatores que possam os distinguir.

O Estado Democrático, neste sentido, apresenta-se como um Estado em que a vontade popular constitui algo supremo, no qual, o acesso à justiça sob a égide dos direitos, deve ser efetivamente assegurado, não apenas nos preceitos da Constituição, mas na prática.

O direito deve ser visto no âmbito do Estado Democrático de Direito como um caminho que garante a justiça, pois é através dele que se tem conhecimento do que se tem direito e quais ferramentas devem utilizar para consegui-lo.

Não há mais espaço, no Estado Democrático de Direito, para o entendimento de que a justiça visa a realizar o direito. Não. É o direito que deve ser utilizado como meio para se alcançar a justiça, entendido como normas positivadas e supra legais (ou naturais como querem os jusnaturalistas). (RANGEL, 2001 p.4)

A colaboração e a conscientização dos magistrados no exercício das suas funções, levando em consideração o papel social que este desempenha na comunidade, é um dos fatores que idealiza essa inserção da população em geral na luta pelos seus Direitos. Os magistrados além de contribuir para uma sociedade mais justa, aplicando as normas de forma corretas no caso concreto, podem também interpretar a linguagem jurídica de forma a se tornar acessível a todos, visto que a linguagem jurisdicional, na maioria das vezes, é incompreensível aos que não tem conhecimento da técnica.

Nalini (1997) acrescenta ainda que, além do magistrado, as escolas de Direito e magistratura devem priorizar o aspecto ético o aspecto ético da profissionalização e a facilidade de técnica para se conseguir a eficiência.

As Escolas precisam, mais do que nunca, enfatizar o aspecto ético da profissionalização, pois o juiz consciente se condói da situação dos excluídos da justiça e se preocupa com a técnica facilitadora da eficiência no desempenho. (NALINI, 1997)

O poder público, além dos magistrados, também tem o papel importante e facilitador para o acesso ao judiciário. Este pode atuar de forma ágil, eficaz, exigindo a rapidez e eficiência no processo e possibilitando também a disseminação das leis, as quais as pessoas possam ter acesso ao que é de direito.

O Judiciário deve assegurar a todos a efetividade dos direitos protegidos e não apenas sua normatividade. Não basta ao indivíduo a certeza de que todas as decisões dos órgãos do poder judiciário serão públicas e fundamentadas todas as decisões, sob pena de nulidade (cf. art. 93, IX da CRFB). É necessário muito mais 
do que isso. É imprescindível a operacionalização dessa regra constitucional dentro do processo. (RANGEL, 2001 p.2)

O papel em geral dos operadores do Direito, deve representar uma função social, preocupada principalmente com a garantia dos direitos coletivos e individuais da população, tornando-se uma muralha que impeça as violações, descasos e arbitrariedades existentes contra a sociedade. Através da interpretação consciente e fidedigna da lei no caso concreto, deve-se buscar a efetivação da justiça de forma leal, justa, transparente e eficaz, para que se constitua e se contribua para a consolidação do exercício pleno do Estado Democrático de Direito.

\section{CONCLUSÃO}

Concluímos, portanto, que a justiça está assegurada formalmente através de normas constitucionais que expressam o princípio da igualdade e da isonomia constitucional. No entanto, o que trouxemos para esse artigo é uma discussão a respeito das deficiências jurisdicionais, as contradições entre o que é dito e o que é feito. Pois aquilo que é expresso na Constituição é requisito meramente formal em respeito a um regime Democrático que adotamos em nosso país. Porém, podemos observar nas passagens desse artigo as inúmeras restrições e exigências que advém desde um comportamento pessoal que engloba a vestimenta e a linguagem, até as questões sociais que abarca as condições financeiras, o senso dos agentes do campo jurídico, a valorização daqueles dotados de capital cultural e simbólico, que torna a norma um instrumento em favor daqueles que possuem capacidade para efetivá-las. Abandonando o caráter hiperativo das normas, tornando-a possível para uns e impossível para outros que não demandam dessas exigências.

\section{REFERÊNCIAS}

BAHIA, TRIBUNAL DE JUSTIÇA. Institucional. Dezembro de 2009 Disponível em: http://www5.tj.ba.gov.br/index.php

BAHIA, TRIBUNAL DE JUSTIÇA. A estratégia do Tribunal de Justiça da Bahia. Dezembro de 2009. Disponível em: http://www5.tj.ba.gov.br/images/pdf/perfinal.pdf 
OS CAMINHOS DO DIREITO: OBSTÁCULOS, FERRAMENTAS E PROCEDIMENTOS IMPORTANTES PARA SE GARANTIR A EFETIVIDADE DA LEI

DÉBORA SUELEN GOMES DE SOUZA RebecCA TEIXEIRA NEVES

BONAVIDES, Paulo. Ciência Política. 10. ed. Malheiros: São Paulo, 2000

BRASIL. Constituição (1988). Constituição [da] Republica Federativa do Brasil. Brasília, DF: Senado Federal.

CARMO, Suzana J. de Oliveira. 0 que é Jurisdição. Revista Jus Vigilantibus, Terça-feira, $1^{\circ}$ de fevereiro de 2005 Disponível em: http:/ / jusvi.com/artigos/2748

COSTA, Hekelson Bittencourt Viana da. 0 papel do juiz na busca da solução justa do litígio: a busca da verdade real e o princípio da segurança das relações jurídicas. 2005 Disponível em:

http://bdjur.stj.gov.br/xmlui/bitstream/handle/2011/16322/0_papel_do_juiz_na_busca_da_sol u\%C3\%A7\%C3\%A30.pdf?sequence=1

DINIZ, Danielle Alheiros. Responsabilidade civil do Estado pela morosidade na prestação jurisdicional. Jus Navigandi, Teresina, ano 10, n. 563, 21 jan. 2005. Disponível em: <http://jus.uol.com.br/revista/texto/6205>. Acesso em: 31 ago. 2011. FILHO, Francisco das C. Lima. Acesso à Justiça e o Juiz moderno. Revista Datavenia. Ano VI No 60 - Agosto de 2002 Disponível em: http://www.datavenia.net/opiniao/AcessoaJusticaeoJuizmoderno.htm\#_ftn1

KAFTA, Franz. O Processo. Rio de Janeiro: Ed. Abril Cultural, 1975

KAFKA, Franz. A Colônia Penal. São Paulo: Livraria Exposição do Livro, 1965, pp. 71-72

MARTINEZ, Vinício C.. Estado Democrático de Direito Social. Jus Navigandi, Teresina, ano 8, n. 173, 26 dez. 2003. Disponível em: <http://jus.com.br/revista/texto/4613>. Acesso em: 7 set. 2011.

NALINI, José Renato. Novas perspectivas no acesso à justiça. Revista CEJ, V. 1 n. 3 set./dez. 1997 Disponível em: http://daleth.cjf.jus.br/revista/numero3/artigo08.htm

RANGEL, PAULO. 0 juiz garantista. 21 de janeiro de 2001.

Disponível em: http://www.mundojuridico.adv.br/sis_artigos/artigos.asp?codigo=171

Redação Terra. Casal de juízes é condenado por venda de sentenças. 12 de novembro de 2003 Disponível em: http://noticias.terra.com.br/brasil/noticias/0, ,0l209267-El306,00-

Casal+de+juizes+e+condenado+por+venda+de+sentencas.html

RODRIGUES, Pedro Paulo; LASMAR, Gabriela. BELO, Fábio. 0 inacessível campo jurídico: Breve leitura de 0 processo de Kafka, a partir da teoria de Pierre Bordieu. 17 de novembro de 2010 Disponível em:

http://www.pvb.adv.br/site/artigos/o-inacessivel-campo-juridico-breve-leitura-de-o-processode-kafka-a-partir-da-teoria-de-pierre-bourdieu/

SANTOS, Boaventura de Sousa. Para uma revolução democrática da justiça. São Paulo: Cortez, 2007. 
SANTOS, Pablo. O Conceito de Capital Simbólico na obra de Pierre Bourdieu. 13 de dezembro de 2007 Disponível em: http://pt.shvoong.com/social-sciences/1723056-conceito-capitalsimb\%C3\%B3lico-na-obra/\#ixzz1XsH69bb6

SILVA, João Fernando Vieira da. 0 juiz e o acesso à Justiça no Brasil. Jus Navigandi, Teresina, ano 14, n. 2054, 14 fev. 2009. Disponível em: <http://jus.com.br/revista/texto/12314>. Acesso em: 7 set. 2011.

TOMÉ, Levi Rosa. 0 artigo 461 do CPC e a efetividade da prestação jurisdicional. Disponível em:_ww1.anamatra.org.br/sites/1200/1223/00000362.doc

Recebido em: 11.08.2012 / Aprovado em: 30.10.2012 